\title{
Säilörehuksi korjattavan härkäpavun korjuutappiot
}

\author{
Antti Suokannas ${ }^{1)}$, Kaisa Kuoppala ${ }^{2)}$ ja Katariina Manni ${ }^{3)}$ \\ ${ }^{1}$ Luke, Luonnonvarakeskus, Vihreä teknologia, Vakolantie 55, 03400 Vihti, antti.suokannas@luke.fi \\ ${ }^{2}$ Luke, Luonnonvarakeskus, Vihreä teknologia, Tietotie 2C, 31600 Jokioinen, kaisa.kuoppala@luke.fi \\ ${ }^{3}$ HAMK, Hämeen ammattikorkeakoulu, Mustialantie105, 31310 Mustiala, katariina.manni@hamk.fi
}

\section{Tiivistelmä}

Kotimaisen valkuaisomavaraisuuden parantamisesta on keskusteltu pitkään ja useissa julkaisuissa on todettu, että valkuaiskasvien tuotantoalat voisivat lisääntyä merkittävästi nykyisestä. Rehuntuotannossa herne ja härkäpapu voidaan korjata joko puimalla tai säilörehuksi. Sadonkorjuun haasteena on minimoida korjuun yhteydessä syntyvät korjuutappiot. Korjattu sato on aina pienempi kuin biologinen sato johtuen osittain korjuuteknologiasta ja sen myötä syntyneistä korjuutappioista, joita ovat hengitys-, huuhtoutumis- ja varisemistappiot. Korjuutappioilla tässä yhteydessä tarkoitetaan varisemistappioita, joita syntyy korjuukoneen kasville aiheuttaman mekaanisen (niitto, silppuaminen) käsittelyn seurauksena. Tavoitteena oli selvittää härkäpavun korjuutappiot kahdella eri menetelmällä, joista toisessa kasvusto korjattiin suoraan pystykasvustosta ja toisessa niittämällä kasvusto karholle ja esikuivaamalla se ennen korjuuta pyöröpaalaimella.

Härkäpavun korjuukoe tehtiin 5.- 6.8.2014 Hämeen ammattikorkeakoulussa Mustialan opetus- ja tutkimusmaatilalla. Kokeissa koelohkoilta korjattu kasvusto oli Kontu-lajike, joka oli kylvetty kahtena eri ajankohtana, 15.5. ja 22.5. Korjuukoneina oli Luoko-Junkkari -merkkinen suoraa kasvustoa niittävä ja silppuava kaksoissilppuri ja toisena koneketjuna Krone EasyCut -niittomurskain, Krone Comprima pyöröpaalain ja Elhon kiedontalaite. Niittomurskattua karhoa esikuivatettiin 24 h ennen paalausta. Kronen muuttuvakammioisessa paalaimessa käytössä oli $26 \mathrm{kpl}$ silppuavia vastateriä ja verkkosidonta. Paalit kiedottiin välittömästi paalauksen jälkeen.

Korjuutappionäyte imuroitiin $50 \mathrm{~cm}$ x $50 \mathrm{~cm}$ kokoisen metallikehikon rajaamalta alueelta, $5 \mathrm{kpl}$ käsittelyä kohti. Aikaisemmin kylvetyn härkäpavun kuiva-ainesato oli 8770 kg ka ha ${ }^{-1}$ ja myöhemmin kylvetyn $7480 \mathrm{~kg} \mathrm{ka} \mathrm{ha}^{-1}$. Härkäpavun korsien, lehtien ja palkojen variseminen aiheutti korjuutappioita kuiva-ainesadosta laskettuna aiemmin kylvetyllä härkäpavulla kaksoissilppurilla korjattaessa 23,2 \% ja pyöröpaalain-kiedonnassa 12,8 \%. Vastaavasti myöhemmin kylvetyllä härkäpavulla korjuutappiot olivat $14,7 \%$ ja 13,3, \%. Korjuutappioiden osalta voi päätellä, että korjuuajankohta oli optimaalisempi myöhempään kylvetyllä koelohkolla, kun korjuumenetelmä oli kaksoissilppuri. Aikaisemmin kylvetyn lohkon kasvusto oli jo alkanut tuleentua ja se mahdollisesti lisäsi korjuutappioita. Tosin paalausmenetelmän tulokset eivät tue edellä mainittua. Aikaisemmin kylvetty kasvusto oli myös lievästi lakoontunutta. Kirjallisuudessa on mainittu kokoviljasäilörehun varisemistappioiden olleen kaksoissilppurilla korjatulla ohrakokoviljalla alle 2,5 \% ja vehnäkokoviljalla alle $12 \%$ sadosta, kun ajonopeus oli alle $10 \mathrm{~km} / \mathrm{h}$. Loppupäätelmänä voi todeta, että härkäpavun korjuutekniikka vaatii lisätutkimusta.

Tämä tutkimusosio oli osa Palkokasvisäilörehut Pohjois-Savolaisilla maitotiloilla - esiselvitystä.

Asiasanat: Härkäpapu, sadonkorjuukoneet, varisemistappiot, kokoviljasäilörehu 


\section{Johdanto}

Härkäpavun viljelyä lisäämällä on mahdollista lisätä kotimaista valkuaisomavaraisuutta. Rehuntuotannossa härkäpapu voidaan korjata puimalla tai säilörehuksi. Korjuu säilörehuna asettaa haasteita korjuutekniikalle, jota on vuosikymmenien aikana kehitetty pääasiassa nurmikasvien vaatimuksia huomioon ottaen. Sadonkorjuun yhtenä haasteena on minimoida korjuutappiot. Korjattu sato on aina pienempi kuin biologinen sato johtuen osittain korjuuteknologiasta ja sen myötä syntyneistä korjuutappioista, joita ovat hengitys-, huuhtoutumis- ja varisemistappiot. Korjuutappioilla tässä yhteydessä tarkoitetaan varisemistappioita, joita syntyy korjuukoneen kasville aiheuttaman mekaanisen (niitto, silppuaminen) käsittelyn seurauksena. Tavoitteena oli selvittää härkäpavun korjuutappiot kahdella eri menetelmällä, joista toisessa kasvusto korjattiin suoraan pystykasvustosta ja toisessa niittämällä kasvusto karholle ja esikuivaamalla se ennen korjuuta pyöröpaalaimella.

\section{Aineisto ja menetelmät}

Elokuun alussa 2014 tehtiin härkäpavun korjuukoe Hämeen ammattikorkeakoulussa Mustialan opetusja tutkimusmaatilalla. Koelohkoilta korjattu kasvusto oli Kontu-lajike, joka oli kylvetty 15.5. ja 22.5. . Suoraa kasvustoa niittävänä ja silppuavana korjuukoneena oli Luoko-Junkkari-kaksoisilppuri. Toisena koneketjuna oli Krone EasyCut 3210 CV-niittomurskain jonka työleveys oli 3,2 m (kuva 1), Krone Comprima -pyöröpaalain ja Elhon kiedontalaite

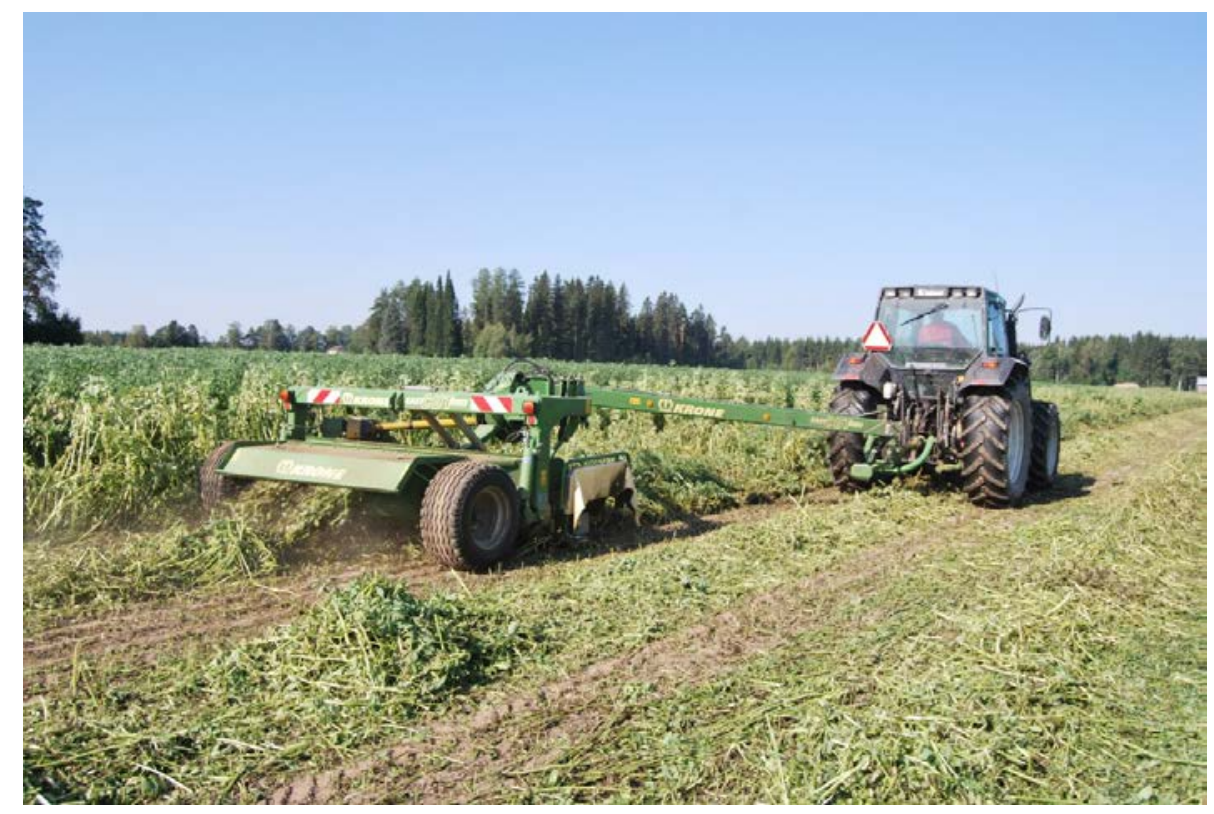

Kuva1. Härkäpavun niitto hinattavalla niittomurskaimella, jonka työleveys oli 3,2 m. Koneen murskainosa oli varstatyyppinen V-mallisin sormin varustettu.

Kokeen kasvusto niitettiin 5.8.. Niitto aloitettiin klo 10.00 ensin aiemmin kylvetyn lohkon niitolla ja heti sen perään myöhemmin kylvetyllä lohkolla. Niittokorkeus säädettiin $10 \mathrm{~cm}$ sängen pituuteen. Murskainosassa ei ollut erillistä säätöä, koska siinä ei ollut vastalevyä tai vastakampaa. Karhon leveys säädettiin 120 cm:iin, mutta se vaihteli välillä 115-125 cm. Karhotinpeltien leveys oli $80 \mathrm{~cm}$ kapeimmalta ja $120 \mathrm{~cm}$ leveimmältä kohdalta.

Niittomurskaimella niitettiin neljä koneen leveyttä molemmissa koelohkoissa. Niitettyä karhoa esikuivattiin 27 tuntia, jonka jälkeen se korjattiin pyöröpaalaimella paaliin ja paalit kiedottiin muovikalvoon välittömästi paalauksen jälkeen.

Niittoa seuraavana päivänä 6.8. kasvusto korjattiin suoraan pystykasvustosta Luoko-Junkkari 170 kaksoissilppurilla (Kuva 2.). Silppurin edessä olevan renkaan ja nostolaitteen avulla säädettiin oikea 
työkorkeus. Säätöpyörää laskettiin niin, että sängen pituus oli noin $10 \mathrm{~cm}$. Heti kaksoissilppurilla tehdyn korjuun jälkeen otettiin korjuutappionäytteet.

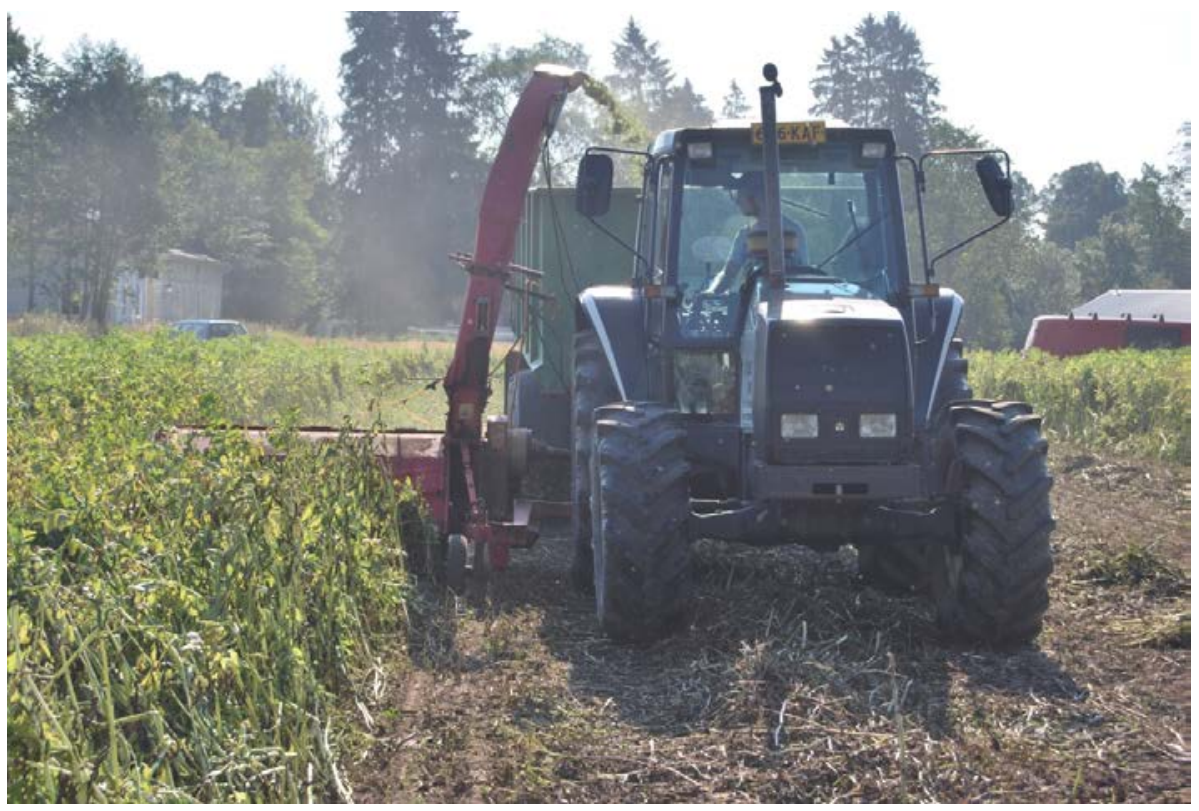

Kuva 2. Härkäpavun toisena korjuukoneena oli kasvustoa suoraan niittävä kaksoissilppuri, jonka työleveys oli $1,7 \mathrm{~m}$.

Samana päivänä kello 13 tienoilla edellisenä päivänä niitetyt karhot paalattiin Krone Comprima V 150XC muuttuvakammioisella pyöröpaalaimella (Kuva 3.), jossa paalin halkaisijaa voidaan säätää välillä 125 - 150 cm:ä. Halkaisija säädettiin siten, että paaleista tuli $145-150$ cm:ä. Paalin leveys oli $122 \mathrm{~cm}$. Paalattaessa ajonopeus oli $6 \mathrm{~km} / \mathrm{h}$. Paalaimessa oli verkkosidontalaite. Verkkoa kiedottiin 2,5 kierrosta paalia kohti. Paalaimen kaikki 26 vastaterää olivat käytössä. Paalaajan ajonopeus oli noin 6 $\mathrm{km} / \mathrm{h}$. Kiedontatraktorin etukuormaimessa oli hydraulipaineen mittaukseen perustuva vaaka, jolla paalit punnittiin. Paalit kiedottiin Elhon Softliner 1400 nostolaitesovitteisella kiedontalaitteella (Kuva 4.). Valkoinen muovikalvo oli leveydeltään 750 mm ja sitä kiedottiin 8 kerrosta paalia kohti.
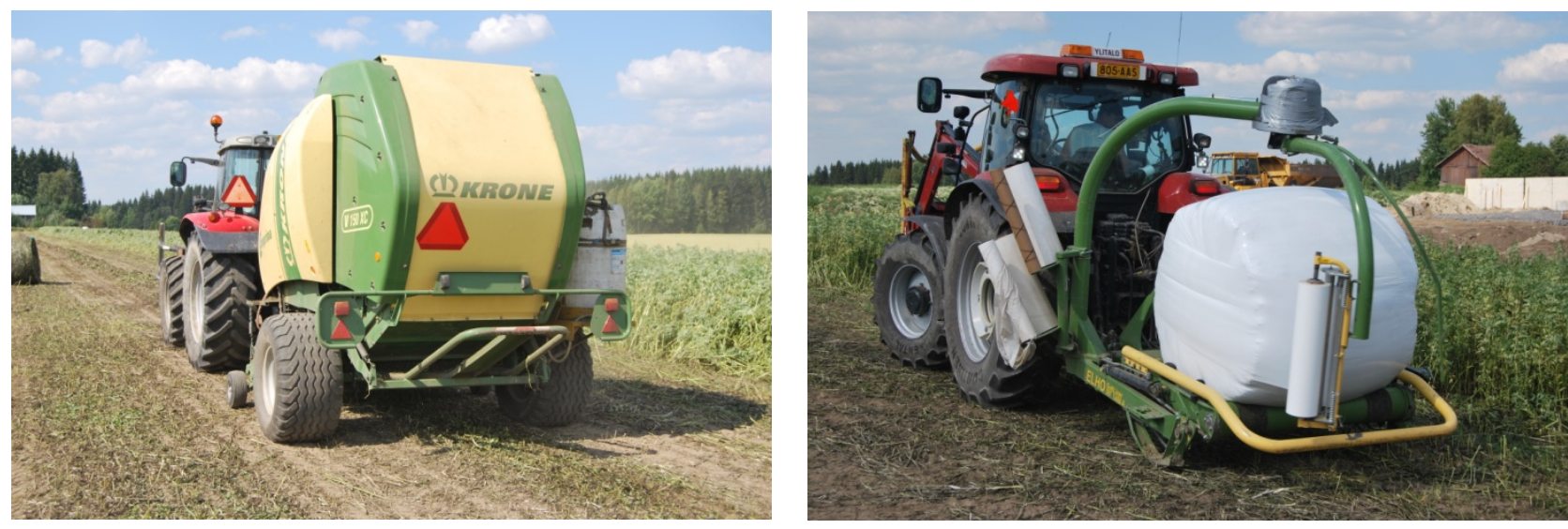

Kuvat 3 ja 4. Vuorokauden esikuivauksen jälkeen härkäpapukarho paalattiin ja paalit kiedottiin muovikalvoon.

Sää niittopäivänä ja seuraavana varsinaisena korjuupäivänä oli aurinkoinen ja erittäin lämmin, lämpötila päivällä oli $25-30^{\circ} \mathrm{C}$. Tuuli oli alle $5 \mathrm{~ms}^{-1}$.

\section{Korjuutappionäytteet}


Korjuutappionäytteitä otettiin 20 kappaletta korjuumenetelmää ja kylvöajankohtaa kohti eli yhteensä $80 \mathrm{kpl}$. Tappionäyte imuroitiin $50 \mathrm{~cm}$ x $50 \mathrm{~cm}$ kokoisen metallikehikon rajaamalta alueelta. Neljä kehikollisesta eli osanäytettä oli pinta-alaltaan $10000 \mathrm{~cm}^{2}=1 \mathrm{~m}^{2}$. Toistoja tehtiin siis $5 \mathrm{kpl}$ käsittelyä kohti.

\section{Näytteiden analysointi}

Näytteisiin tuli imuroitaessa mukaan jonkin verran maa-ainesta ja se jouduttiin seulomaan ennen näytteen kuivausta. Näytteitä kuivattiin $103{ }^{\circ} \mathrm{C}$ lämpötilassa 24 tuntia, jonka jälkeen näytteet punnittiin.

\section{Tulokset ja tulosten tarkastelu}

\section{Korjuutappiot}

Korjuutappiot laskettiin sekä absoluuttisina että suhteellisina arvoina. Aikaisemmin kylvetyn härkäpavun kuiva-ainesato oli 8770 kg KA ha ${ }^{-1}$ ja myöhemmin kylvetyn 7480 kg KA ha ${ }^{-1}$.

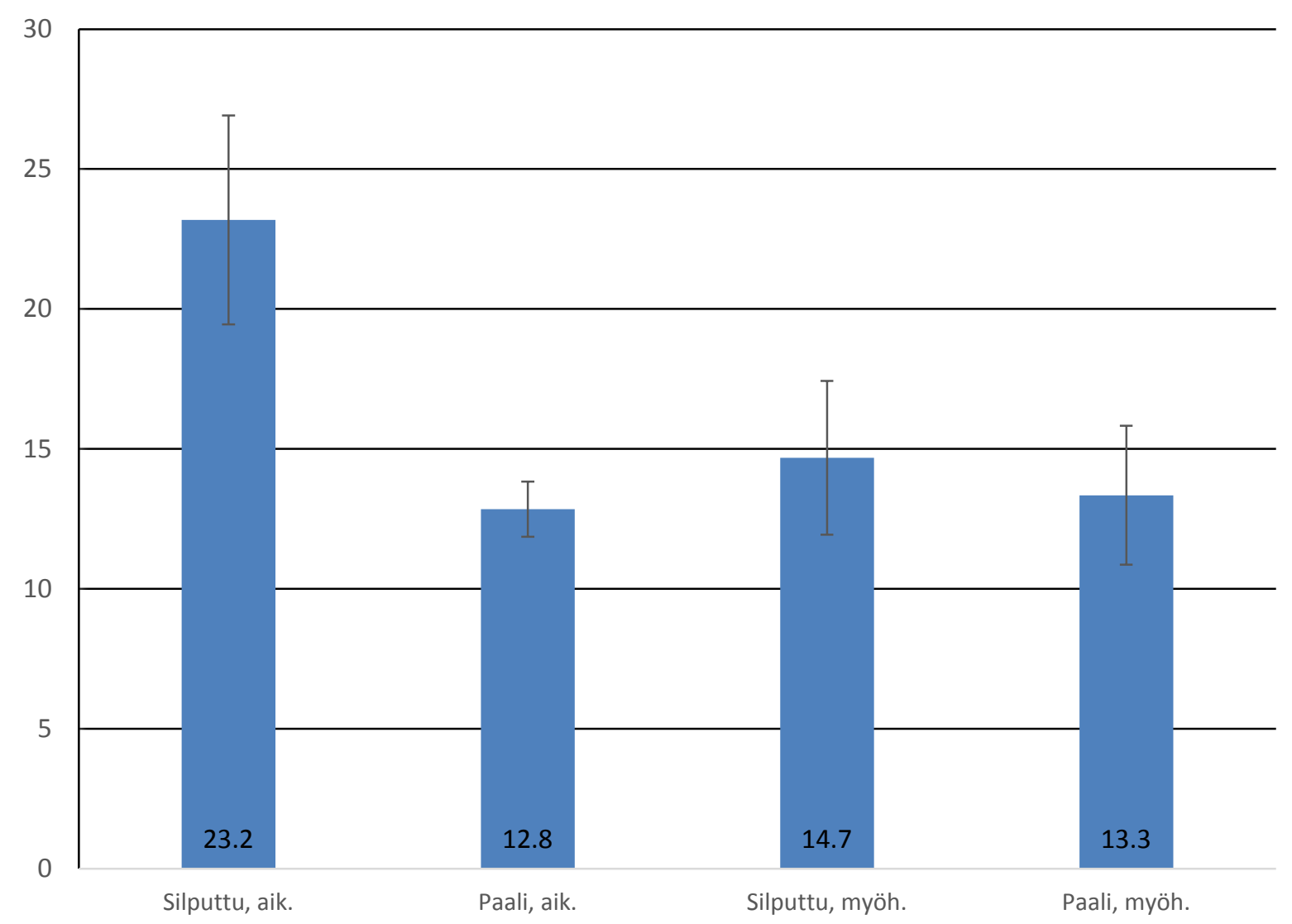

Kuva 5. Kaksoissilppurin ja paalausmenetelmän korjuutappiot ovat aikaisin ja viikkoa myöhemmin kylvetyllä Kontu-härkäpavulla laskettu prosentteina kuiva-ainesadosta. Pylväsdiagrammiin on lisätty virhepalkit laskettuna 95 \% luottamusväliä käyttäen.

Myöhemmin kylvetyn härkäpavun korjuutappiot olivat niin kaksoissilppurimenetelmässä kuin pyöröpaalain-kiedontamenetelmässäkin suhteellisen alhaiset, 14,7 ja 13,3 \% -kuiva-ainesadosta (Kuva 5.). Härkäpavun korsien ja palkojen variseminen aiheutti aiemmin kylvetyn härkäpavun suuret korjuutappiot. Kaksoissilppurilla 23,2 \% kuiva-ainesadosta varisi maahan ja jäi korjaamatta. Korjuutappiotulosten osalta voi päätellä, että korjuuajankohta oli oikeampi myöhemmin kylvetyn koelohkon osalta. Aikaisemmin kylvetyn lohkon kasvusto oli tuleentuneempi ja näytti "ränsistyneeltä" ja lisäksi se oli lievästi lakoontunut. Kasvuston tuleentumisaste saattoi vaikuttaa kasvaneisiin korjuutappioihin. Tosin paalausmenetelmän tulokset eivät tue edellä mainittua Aikaisemmassa 
tutkimuksessa viljasta tehdyllä kokoviljasäilörehulla varisemistappiot kaksoissilppurikorjuussa olivat ohrakokoviljalla alle 2,5 \% ja vehnäkokoviljalla alle $12 \%$ sadosta kun ajonopeus oli alle $10 \mathrm{~km} / \mathrm{h}$ (Suokannas et al. 2003). Samassa kokeessa todettiin, että massavirta ja ajonopeus vaikuttavat varisemistappioiden määrään.

Sängen pituus vaihteli aikaisemmin kylvetyllä lohkolla kaksoissilppurilla korjattaessa 8 -15 cm:n välillä johtuen osittain kasvuston lakoisuudesta. Myöhemmin kylvetyn lohkon korjuussa kaksoissilppurin työjälki oli hyvä ja sängen pituus tasamittainen, $8-10 \mathrm{~cm}$. Edellisenä päivänä niittomurskaimella niitetyn härkäpavun sänki oli myös 8 -10 cm mittainen.

Koepaaleja niittomurskatulta alalta tuli 7 kpl ja paalien paino vaihteli 890 kg:n ja 1060 kg:n välillä ollen keskimäärin 980 kg. Paalit eivät olleet muodoltaan aivan optimaalisia vaan vaipan keskiosasta tuli ulkonevia eli kuperia.

\section{Muita havaintoja korjuussa}

Aikaisemmin kylvettyä kasvustoa korjattaessa kaksoissilppurilla koneen oikeanpuoleinen kasvustoa ohjaava lyhyt metallikärki kasasi hiukan kasvustoa. Pienen säätötoimenpiteen jälkeen kasvuston kasaantuminen väheni. Sen sijaan myöhemmin kylvettyä kasvustoa korjattaessa kaksoissilppurin työjälki oli hyvä. Pystykasvuston ja säilörehuasteella olevan kasvuston korjuu onnistuu kaksoissilppurilla tietyin reunaehdoin tai rajoittein. Korjuu on hidasta johtuen kapeasta, $160 \mathrm{~cm}$ käytännön työleveydestä, ja $5 \mathrm{~km} / \mathrm{h}$ ajonopeudesta, jonka seurauksena työsaavutus on vaatimaton. Menetelmä sopii pienille korjuualoille. Suositeltava paalin halkaisija kokeen perusteella on noin 100 $120 \mathrm{~cm}$ luonnollisesti edellyttäen, että paalain on muuttuvakammioinen ja paalikokoa voidaan säätää portaattomasti. Painavaa paalia on hankala käsitellä. Jos paalain on kiinteäkammioinen, olisi hyvä jos kammion halkaisija olisi maksimissaan noin $125 \mathrm{~cm}$. Em. luku on käytännössä juuri monen pienen kiinteäkammioisen pyöröpaalaimen tekemän paalin halkaisija.

\section{Johtopäätökset}

Härkäpavun korjuussa säilörehuksi voi käyttää suoraniittomenetelmää tai erillistä niitto- ja korjuuvaihetta sisältävää menetelmää. Kaksoissilppuri soveltuu pienten, muutaman hehtaarin korjuualojen rehuntekoon, mutta isoilla korjuualoilla sen alhainen työsaavutus on rajoitteena. Myös kaksivaiheista korjuumenetelmää, kuten niitto ja paalaus, voi käyttää härkäpavun korjuussa. On kuitenkin muistettava, että kasvusto kuivuu hyvin hitaasti karhossa hyvissäkin sääolosuhteissa ja alhaisen KA-pitoisuuden seurauksena yksittäisen paalin paino voi olla jopa yli 1000 kg kun paalin halkaisija on noin 145 cm:ä. Korjuutappioissa pitäisi pyrkiä alle $10 \%$ ja mieluummin noin $5 \%$ tappioihin sadosta. Nyt kokeissa parhaimmillaan saavutettiin noin $13 \%$ korjuutappiot. Härkäpavun korjuutekniikka vaatii lisätutkimusta, jossa yhtenä mielenkiintoisena tekniikkana voi olla riipijäpöydän hyödyntäminen.

\section{Kirjallisuus}

Suokannas, A., Pehkonen, A., Mäkinen, H., Tuori, M. \& Pentti, S. 2003. Kokoviljasäilörehu karjatilalla. Maa- ja elintarviketalous 40: 76 s. +1 liite. 